clonally heterogeneous, and that they have an important immunoregulatory role. $A$ priori it seems highly likely that they do.

Moreover, it makes sense that just as environmental antigens stimulate and recruit relevant $T$ and $B$ cell clones into the recirculating, long-lived lymphocyte pool, the antibodies and receptor-bearing cells produced in the course of these responses should stimulate and recruit anti-idiotypereactive clones into the pool; thus, the immune system would organise itself into an idiotype-based network. It should not be difficult to establish that such a network is important in immunoregulation: if eliminating antiidiotype-reactive $T$ and $B$ cells from a cell population markedly alters the response of the idiotype-bearing clones to the appropriate antigen, the point would be made. From a practical standpoint, the TEPC 15 idiotype response to phosphorylcholine $\mathrm{e}^{\mathrm{x}, 13,13,18}$ would be an attractive system for such an experiment, but ultimately it will be important to demonstrate an effect in a non-restricted, clonally heterogeneous response.

As Jerne has pointed out", the major weakness in an immune network theory at the moment is the incompleteness of our knowledge of the component parts (immunologists are still subdividing $T$ and $B$ cells into an increasing number of subclasses, and the end is not yet in sight) and our ignorance of the mechanisms involved in positive and negative interactions between the parts. The task is clear, and it seems unlikely that mathematical model-building ${ }^{22.23}$ will be of great value until more information about the elements in the network is available. In the meantime, the lack of detail makes it possible to use the network theory to explain various immunological paradoxes that are difficult to explain in other ways ${ }^{2}$. For example, it provides, in principle, a way out of the Oudin-Cazenave enigma ${ }^{24}$, which is the observation that antibodies produced against two non-cross-reacting epitopes of one antigen molecule may have similar idiotypic determinants. It can also explain another of Oudin's paradoxical observations ${ }^{25}$ - that immunisation results in the production of nonspecific $\mathrm{Ig}$ molecules bearing the same idiotypes as the specific antibodies; in fact, this suggests the existence of the "unspecific parallel set" of lymphocytes in Jerne's network (see Fig.).

\section{An allotype network}

The dramatic observations of the Herzenbergs and their colleagues ${ }^{26}$ on chronic allotype suppression have uncovered another type of lymphocyte network, based on allotype rather

\title{
Volcano spacing in East Africa
}

from Peter J. Smith

THE near-rectilinear pattern of volcanoes in the Galapagos Islands was first noticed by Darwin (in Geological Observations on Volcanic Islands, London, 1891) and the near-uniform spacing of Hawaiian volcanoes was first observed by Green (in Vestiges of the Molten Globe, Honolulu, 1887). Since then, numerous workers have claimed to detect regularities in volcano siting, and some have pointed out that the spacings of oceanic volcanoes in particular appear to be roughly equal to the thickness of the local crust. More systematic attempts to relate volcano spacing to crustal thickness were doomed to failure, however, because (as we now know) the crust is not the correct unit to consider in this context.

Interest in the problem of volcanic intervals therefore largely died out until in 1974 Vogt (Earth planet. Sci. Lett. 21, 235; 1974) revived it in the light of modern ideas on Earth structure. Vogt found that within oceanic provinces volcano spacings are indeed remarkably uniform. In 'continental' subduction zones volcanoes are typically $70 \mathrm{~km}$ apart whereas in island arcs they are $55 \mathrm{~km}$ apart. The separations of volcanoes associated with 'hot spots', on the other hand, increase with the age of the surrounding oceanic crust. But what, figuratively speaking, links all these volcanoes is the thickness not of the crust but of the lithosphere. Thus Vogt was able to show that within any given volcanic province the distance between adjacent volcanoes is roughly

than idiotype. Allotypes are alloantigenic epitopes on Ig molecules which are unrelated to the antigen binding site and have no known functional significance. In [SJL(Ig-1b) $\times$ BALB $/ c$ (Ig-1a)] $F_{1}$ mice, perinatal exposure to antibodies directed against Ig-1b allotype determinants (present on IgG molecules) results in the generation of suppressor $T$ cells which specifically inhibit the production of all antibodies bearing the Ig- $1 \mathrm{~b}$ allotype but not antibodies bearing the other parental allotype (Ig-la). Herzenberg et al. ${ }^{26}$ have now shown that the suppressor $T$ cells in these allotype-suppressed mice do not directly act on Ig-1b B cells, as originally assumed; rather, they suppress a specific class of helper $T$ cells which normally help Ig-1b B cells to differentiate into Ig-1b antibodysecreting cells. Besides indicating that $\mathbf{T}$ cell suppression of $\mathbf{B}$ cell responses equal to the thickness of the local lithosphere.

But is this also true for continental volcanism? To find out, Mohr and Wood (Earth planet. Sci. Lett. 33, $126 ; 1976)$ have examined volcanoes along the northern section of the East African rift (roughly $1.5 \mathrm{~N}-5^{\circ} \mathrm{S}$ ). This is a particularly suitable area because. although data are fewer, lithospheric thicknesses are generally better determined than in oceanic zones and are known to cover a much wider range. In any event, there are sufficient data to allow Mohr and Wood to show convincingly that the volcano spacing $=$ lithospheric thickness relationship holds good for East Africa as well and is independent of the type of volcanic rock involved.

Why the relationship holds, apparently universally, is less clear, however. Vogt made two suggestions: first, that a volcano taps all magma within a given radius (a 'scavenging radius') related to lithospheric thickness through a conical volcanic conduit of fixed angle $\left(25^{\circ}\right)$ and, second, that volcanic sites are controlled by lithospheric fracture grids with spacings related to lithospheric thickness. He favoured the latter mechanism, though leaving open the question of whether the grids predate, or are contemporaneous with, the magmatic activity. By contrast, in a situation in which the crust is exposed Mohr and Wood find no evidence at all of volcanic control by pre-existing fracture grids, although again the possibility of contemporaneous rifting remains open. may act indirectly by way of $\mathrm{T}$ helper cells, as is probably also the case in carrier-specific $T$ cell suppression ${ }^{2-}$. these striking experiments demonstrate that, in these mice at least, there are allotype-specific $T$ helper cells, which help only B cells bearing the Ig-1b allotype, and suppressor $T$ cells which specifically suppress these allotype-specific $\mathrm{T}$ helper cells. These three sets of cells constitute a lymphocyte network organised around allotype, which, unlike an idiotype-based network, is independent of antigen specificity and would therefore include many lymphocyte sets functionally linked in an idiotype network.

There are however difficulties in inducing chronic allotype suppression using other mouse strain combinations ${ }^{28}$, and it is not clear whether allotype networks are the exception or the rule. Nor is it obvious what pur- 